Queries for apls-64-12-15

This manuscript/text has been typeset from the submitted material. Please check this proof carefully to make sure there have been no font conversion errors or inadvertent formatting errors. Allen Press. 


\title{
Identification of Clay Minerals by Infrared Spectroscopy and Discriminant Analysis
}

\author{
MICHAL RITZ,* LENKA VACULÍKOVÁ, and EVA PLEVOVÁ \\ VŠB-Technical University Ostrava, 17. listopadu 15, 70833 Ostrava-Poruba, Czech Republic (M.R.); and Institute of Geonics of the AS CR, \\ Studentská 1768, 70800 Ostrava-Poruba, Czech Republic (L.V., E.P.)
}

\begin{abstract}
Identification of clay minerals based on chemometric analysis of measured infrared (IR) spectra was suggested. IR spectra were collected using the diffuse reflection technique. Discriminant analysis and principal component analysis were used as chemometric methods. Four statistical models were created for separation and identification of clay minerals. More than 50 samples of various clay mineral standards from different localities were used for the creation of statistical models. The results of this study confirm that the discriminant analysis of IR spectra of clay minerals could provide a powerful tool for identification of clay minerals. Differentiation of muscovite from illite and identification of mixed structures of illitesmectite were achieved.
\end{abstract}

Index Headings: Clay minerals; Identification; Infrared spectroscopy; IR spectroscopy; Discriminant analysis; DA; Principal component analysis; PCA.

\section{INTRODUCTION}

Knowledge of mineral composition is essential to characterize the geochemical and physico-mechanical properties of rocks. Type and content of clay minerals present in rocks have a significant influence on the behavior and properties of rocks as well as on the whole rock massif.

In general, several conventional analytical methods exist that can be used to examine the mineral composition of rocks: optical microscopy, electron microscopy, X-ray diffraction (XRD), Fourier transform infrared (FT-IR) spectroscopy, simultaneous thermogravimetry and differential thermal analysis (TG/DTA), and bulk chemistry analysis. ${ }^{1-5}$ Unfortunately, the exact identification of clay minerals by means of these methods is rather complicated and often inaccurate. The main analytical difficulties are related to variable chemical composition and common structural disorders of clay minerals. In addition, the individual clay minerals occur in the form of mixtures (illite-montmorillonite, chlorite-montmorillonite, etc.) with various ratios of particular clay minerals.

The current Fourier transform infrared (FT-IR) spectroscopy represents a fast, reliable, and efficient tool for mineral analysis. Very useful for processing of IR spectra are multivariate statistical methods. The primary advantage of multivariate statistical methods is their capability to extract required spectral information from IR spectra and explore this information for qualitative or quantitative applications. The most frequently used multivariate statistical methods (often called chemometric methods) are factor analysis (FA), principal component analysis (PCA), discriminant analysis (DA), principal component regression (PCR), multiple linear regression (MLR), and partial least squares regression (PLS). DA, FA, and PCA are very useful tools for qualitative analysis.

Received 19 February 2010; accepted 17 September 2010.

* Author to whom correspondence should be sent. E-mail: michal.ritz@ vsb.cz.
Discriminant analysis allows the quantification of the probability with which an object can be assigned to an individual class. The discriminant function, which gives the maximum separability for objects from different classes, is generated by DA. The major purpose of DA is to assign unknown objects to one of several classes. This method can be used either for prediction of analyzed samples into predefined classes or for explanation of the differences between classes. ${ }^{6}$ The sample is classified as a member of the appropriate class predominately according to the value of the Mahalanobis distance (MD). The MD between spectra from two samples $\mathbf{x}_{i}$ and $\mathbf{x}_{j}$ is defined as:

$$
\mathbf{M D}_{i j}=\sqrt{\left(\mathbf{x}_{i}-\mathbf{x}_{j}\right)^{\mathrm{T}} \mathbf{S}^{-1}\left(\mathbf{x}_{i}-\mathbf{x}_{j}\right)}
$$

where $\mathbf{x}_{i}$ and $\mathbf{x}_{j}$ are the measured spectra and $\mathbf{S}$ is the covariance matrix. ${ }^{7}$

There are several methods of discriminant analysis described in the literature: Fisher's linear discrimination function (LDF), linear discriminant analysis (LDA), quadratic discriminant analysis (QDA), etc. The major difference between the abovementioned methods of discriminant analysis is in the number of predefined classes. Furthermore, the predefined classes are dependent on the similarity of the covariance matrices. LDF can be applied to two classes only; covariance in the classes must be similar. LDA and QDA can handle more than two classes. The covariance in the classes should be similar for LDA, while QDA can handle very dissimilar covariance matrices.

The fundamental problem of DA for spectral data is the large number of variables. With a large number of variables it is impossible to apply DA to the "raw data"; rather, it is necessary to carry out PCA followed by DA. ${ }^{8}$ PCA is one of the most common multivariate statistical methods. This method allows "extraction" of important information from a data set (e.g., from IR spectra). The results of PCA are the so-called principal components (PCs), which make it possible to dramatically reduce the number of variables in the data set.

Both of the above-mentioned chemometric methods (DA and PCA) are described in many statistical textbooks ${ }^{9,10}$ in full detail. Likewise, DA and/or PCA of IR spectra are used in many studies. ${ }^{11-15}$

This paper describes a chemometric analysis of the IR spectra of clay minerals by PCA and DA. The results of DA can be applied to the identification of clay minerals. PCA was performed to reduce redundant spectral information and find the spectral bands important for successful identification of clay minerals by DA. All IR spectra were collected using the diffuse reflection technique (DRIFT). The aim of the study was the creation of statistical models for identification of clay minerals by discriminant analysis of measured IR spectra. The 
TABLE I. List of samples.

\begin{tabular}{|c|c|c|c|}
\hline Sample & Mineral & Locality & Description \\
\hline Bio1 & Biotite & Ktî́s, Czech Republic & fraction $\leq 5 \mu \mathrm{m}$ \\
\hline $\mathrm{Bio} 2$ & Biotite & Ktîs, Czech Republic & "raw" standard \\
\hline Bio3 & Biotite & Dolní Bory, Czech Republic & fraction $\leq 5 \mu \mathrm{m}$ \\
\hline Mus1 & Muscovite & India & "raw" standard \\
\hline Mus2 & Muscovite & Měděnec, Czech Republic & fraction $\leq 5 \mu \mathrm{m}$ \\
\hline Mus3 & Muscovite & Otov, Czech Republic & fraction $\leq 5 \mu \mathrm{m}$ \\
\hline Mus4 & Muscovite & Měděnec, Czech Republic & "raw" standard \\
\hline Mus5 & Muscovite & Rožná, Czech Republic & fraction $\leq 5 \mu \mathrm{m}$ \\
\hline Mus6 & Muscovite-Chlorite & Měděnec, Czech Republic & "raw" standard \\
\hline Ill1 & Illite & Hungary & fraction $\leq 5 \mu \mathrm{m}$ \\
\hline $\mathrm{Ill} 2$ & Illite (IMt-1) & Montana, USA & fraction $\leq 5 \mu \mathrm{m}$ \\
\hline $\mathrm{Ill3}$ & Illite & Karlov, Czech Republic & "raw" standard \\
\hline $\mathrm{Ill4}$ & Illite (IMt-2) & Montana, USA & "raw" standard \\
\hline $\mathrm{Ill5}$ & Illite (IMt-1) & Montana, USA & jet mill \\
\hline Ill6 & Illite (IMt-2) & Montana, USA & "raw" standard \\
\hline $\mathrm{Ill7}$ & Illite-Smectite (ISCz-1) & Czechoslovakia & "raw" standard \\
\hline Ch1 & Chlorite (CCa-2) & California, USA & fraction $\leq 5 \mu \mathrm{m}$ \\
\hline $\mathrm{Ch} 2$ & Chlorite & Letovice, Czech Republic & fraction $\leq 5 \mu \mathrm{m}$ \\
\hline $\mathrm{Ch} 3$ & Chlorite & Orlické hory, Czech Rep. & fraction $\leq 5 \mu \mathrm{m}$ \\
\hline $\mathrm{Ch} 4$ & Chlorite (CCa-2) & California, USA & "raw" standard \\
\hline Ch5 & Chlorite (CCa-2) & California, USA & jet mill \\
\hline Kao1 & Kaolinite & Božíčany, Czech Republic & "raw" standard \\
\hline $\mathrm{Kao} 2$ & Kaolinite & Horní Bříza, Czech Republic & "raw" standard \\
\hline Kao3 & Kaolinite (KGa-1b) & Georgia, USA & fraction $\leq 5 \mu \mathrm{m}$ \\
\hline $\mathrm{Kao} 4$ & Kaolinite & Kadañ, Czech Republic & "raw" standard \\
\hline Kao5 & Kaolinite & Kaznějov, Czech Republic & "raw" standard \\
\hline Kao6 & Kaolinite & Sedlec, Czech Republic & "raw" standard \\
\hline $\mathrm{Kao} 7$ & Kaolinite & Únavov, Czech Republic & "raw" standard \\
\hline Kao8 & Kaolinite (KGa-1b) & Georgia, USA & "raw" standard \\
\hline Kao9 & Kaolinite (KGa-2) & Georgia, USA & "raw" standard \\
\hline Kao10 & Kaolinite & Sedlec, Czech Republic & "raw" standard \\
\hline Kao11 & Kaolinite & Sedlec, Czech Republic & fraction $\leq 5 \mu \mathrm{m}$ \\
\hline Dic1 & Dickite & Krásno, Czech Republic & fraction $\leq 5 \mu \mathrm{m}$ \\
\hline Hal1 & Halloysite & Bílá Hora, Slovakia & "raw" standard \\
\hline Mon1 & Montmorillonite & Ivančice, Czech Republic & fraction $\leq 5 \mu \mathrm{m}$ \\
\hline Mon2 & Montmorillonite & Jelšový potok, Slovakia & fraction $\leq 5 \mu \mathrm{m}$ \\
\hline Mon3 & Montmorillonite (SWy-1) & Wyoming, USA & "raw" standard \\
\hline Mon4 & Montmorillonite (SWy-1) & Wyoming, USA & fraction $\leq 5 \mu \mathrm{m}$ \\
\hline Mon5 & Montmorillonite (SWy-2) & Wyoming, USA & "raw" standard \\
\hline Mon6 & Montmorillonite (SAz-2) & Arizona, USA & fraction $\leq 5 \mu \mathrm{m}$ \\
\hline Mon7 & Montmorillonite (SAz-2) & Arizona, USA & "raw" standard \\
\hline Mon8 & Montmorillonite (STx-1b) & Texas, USA & "raw" standard \\
\hline Non1 & Nontronite (Nau-1) & Uley Mine, South Australia & "raw" standard \\
\hline Non2 & Nontronite (Nau-2) & Uley Mine, South Australia & "raw" standard \\
\hline Hecl 1 & Hectorite (SHCa-1) & California, USA & "raw" standard \\
\hline Ver1 & Vermiculite & China & expanded \\
\hline Ver2 & Vermiculite & Aldrich standard & expanded \\
\hline Ver3 & Vermiculite & Aldrich standard & expanded, jet mill \\
\hline Ver4 & Vermiculite & Letovice, Czech Republic & not expanded \\
\hline Ver5 & Vermiculite & Brasil & not expanded \\
\hline Ver6 & Vermiculite & Brasil & not expanded, jet mill \\
\hline
\end{tabular}

advantage of using DA for identification of clay minerals is, e.g., the ability to identify mixed structures of clay minerals. This method of identification has not been reported so far for clay minerals.

\section{MATERIALS AND METHODS}

Samples of Minerals. This research focuses on the basic clay mineral specimens (kaolinite, montmorillonite, nontronite, illite, chlorite, and vermiculite), including micas (muscovite and biotite). These mineral standards were obtained from the collection of minerals available at the Institute of Geonics, Nanotechnology Centre of VŠB-Technical University Ostrava and from the Source Clays Repository of the Clay Minerals Society, USA. Fifty-one samples of mineral standards were collected for the preparation of statistical models. Some of the mineral standards were treated by jet mill; others were prepared by sedimentation to obtain a fraction grain size of less than 5 $\mu \mathrm{m}$. Some standards were used as unmodified ("raw" standards). A list of all samples used as mineral standards is shown in Table I.

Fourier Transform Infrared Measurements. Approximately 5-10 mg of a mineral standard sample was ground with approximately $400 \mathrm{mg}$ dried $\mathrm{KBr}$. IR spectra were collected from this mixture.

The IR spectra were collected using a Nexus 470 FT-IR spectrometer (ThermoScientific, USA) with DTGS detector. The diffuse reflection measurement technique (DRIFT) was used. The measurement parameters were as follows: spectral region $4000-400 \mathrm{~cm}^{-1}$, spectral resolution $8 \mathrm{~cm}^{-1}$; 128 scans; 


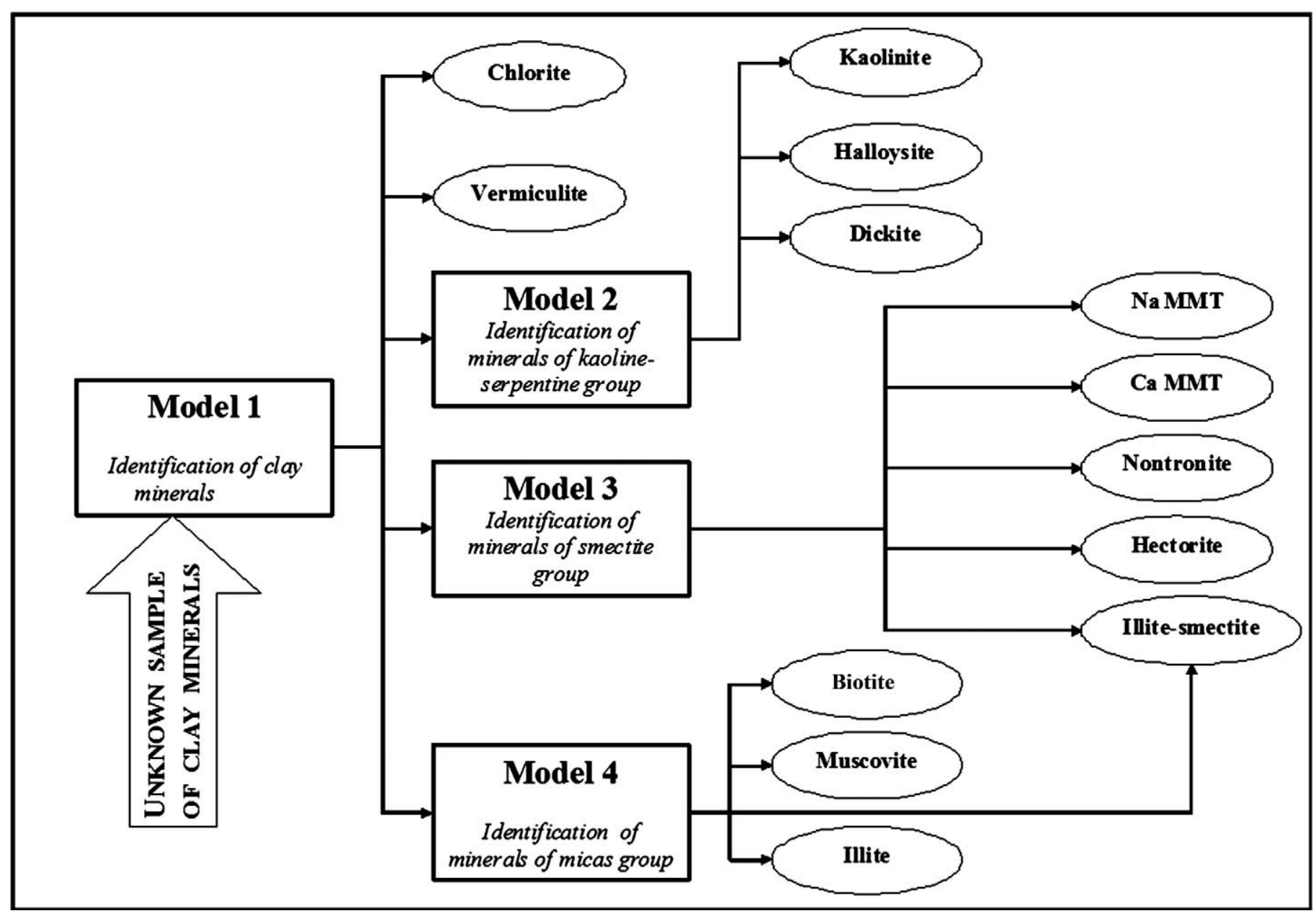

FIG. 1. Scheme of identification of clay minerals by discriminant analysis. Note: Na-MMT: Na-montmorillonite; Ca-MMT: Ca-montmorillonite.

and Happ-Genzel apodization. Freshly dried $\mathrm{KBr}$ was used for the background measurement.

Every sample was prepared and consequently measured several times (three to five times). The mean IR spectrum of every sample was calculated.

Discriminant Analysis. The linear discriminant analysis (LDA) was performed using TQ Analyst software (ThermoScientific, USA). Two spectral regions of each IR spectrum (4000-3000 $\mathrm{cm}^{-1}$ and $1300-400 \mathrm{~cm}^{-1}$ ) were used for DA. A one-point baseline was used in both spectral regions. A multiplicative signal correction of the path length was used for calculation. The Mahalanobis distance was used to formulate the distance between clusters. Before DA, PCA was performed to reduce redundant spectral information. The number of principal components used for the preparation of all models was 10 .

Validation of statistical models has been carried out by means of a validation spectra set (TQ Analyst software does not allow cross-validation for discriminant analysis). The IR spectra of minerals were split into two groups in each class used in DA: a calibration group of spectra and a validation group of spectra. The calibration spectra were used to create a discrimination model; the validation spectra were used to verify this model. Most of the IR spectra in each class were used as calibration spectra; up to three IR spectra in each class were used as validation spectra. There were no validation spectra used in one-member-only classes. The selection of calibration and validation spectra was carried out using TQ Analyst software. The models in this study were considered correct when all validation spectra occurred inside their class clusters. All discrimination models mentioned in this paper fulfill this condition.

\section{RESULTS AND DISCUSSION}

Strategy of Model Creation. The creation of a unique statistical model for all used samples was a primary goal of the authors. During the process of creation of the unique models, however, serious challenges were encountered. Multiple minerals were classified into incorrect classes because of considerable variability in the spectral bands. The solution to this problem was the creation of partial models; four partial models were created in this study. These partial models allow separation and subsequent identification of clay minerals in a few steps. A brief scheme of the identification of clay minerals proposed in this study is shown in Fig. 1.

General discrimination of clay minerals was performed in Model 1. The clay minerals were classified into particular groups of clay minerals in this model: biotite, muscovite-illite, chlorite, kaolin-serpentine, smectite, and vermiculite. The remaining models were created for identification of individual members of selected clay mineral groups. Model 2 allows identification of minerals of the kaolin-serpentine group 


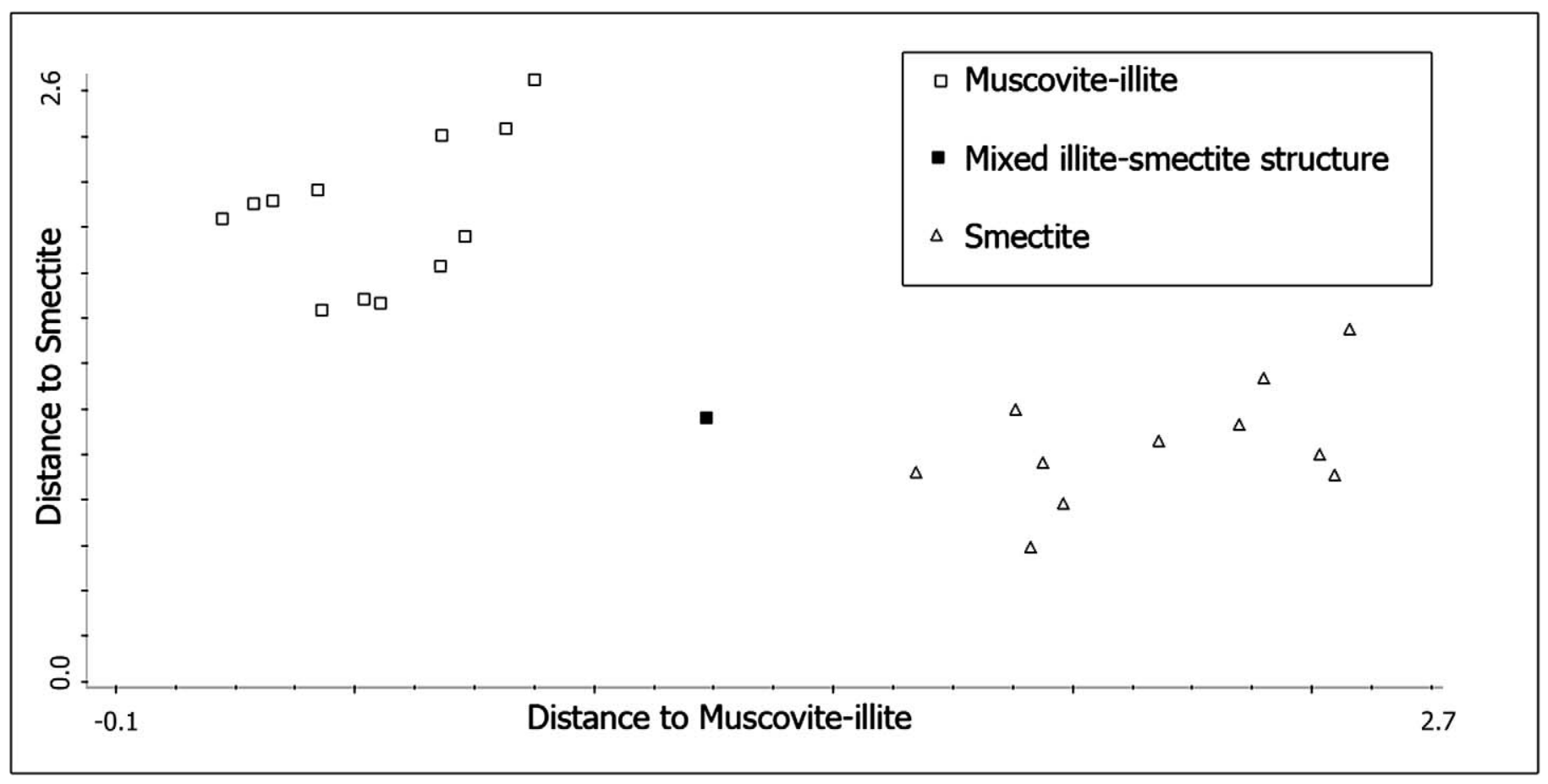

FIG. 2. Mahalanobis distance plot of classes muscovite-illite and smectite (Model 1).

(kaolinite, dickite, and halloysite), Model 3 allows identification of minerals of the smectite group ( $\mathrm{Na}-$ montmorillonite, $\mathrm{Ca}-$ montmorillonite, nontronite, and hectorite), and Model 4 allows identification of micas (biotite and muscovite) and illite.

Model 1: Identification of Clay Mineral Groups. This model was created for classification of clay minerals into particular groups of clay minerals. Classification of clay minerals according to Weiss and Kužvart ${ }^{16}$ was used in this study. Model 1 contained six classes (biotite, muscovite-illite, chlorite, kaoline-serpentine, smectite, and vermiculite). In this model the first two classes represented the mica group of clay minerals; the other classes represented the remaining groups of clay minerals. The mica group had to be split into two classes (biotite and muscovite-illite) because of bad creation of clusters. The biotite class contained only samples of biotite; the muscovite-illite class contained samples of muscovite, illite, and the mixed illite-smectite sample. The chlorite class contained only chlorite samples. The kaoline-serpentine class contained samples of kaolinite, dickite, and halloysite. The smectite class contained samples of montmorillonite, nontronite, and hectorite. The vermiculite class contained only samples of vermiculite.

With the exception of sample I117, all minerals were clearly classified into the appropriate classes after performance of discriminant analysis. The above-mentioned sample (mixed illite-smectite structure) was classified between the muscoviteillite class and the smectite class (Fig. 2).

Ten principal components (PCs) were calculated in Model 1. These ten PCs described $99.9 \%$ of the variance of the spectral information, with nearly $95 \%$ of the variance captured in the first three PCs. The loadings spectrum of the first principal component (PC1) includes spectral bands of kaolinite only: stretching bands of inner-surface hydroxyl groups $\left(3695 \mathrm{~cm}^{-1}\right.$, $3668 \mathrm{~cm}^{-1}, 3652 \mathrm{~cm}^{-1}$, and $3620 \mathrm{~cm}^{-1}$ ), the Si-O stretching band $\left(1100 \mathrm{~cm}^{-1}\right)$, in-plane $\mathrm{Si}-\mathrm{O}$ stretching bands $\left(1030 \mathrm{~cm}^{-1}\right.$ and $1010 \mathrm{~cm}^{-1}$ ), the deformation band of inner-surface hydroxyl groups $\left(915 \mathrm{~cm}^{-1}\right), \mathrm{Si}-\mathrm{O}$ stretching bands $(795$ $\mathrm{cm}^{-1}, 755 \mathrm{~cm}^{-1}$, and $\left.695 \mathrm{~cm}^{-1}\right)$, and deformation bands of $\mathrm{Al}-$ $\mathrm{O}-\mathrm{Si}, \mathrm{Si}-\mathrm{O}-\mathrm{Si}$, and $\mathrm{Si}-\mathrm{O}\left(540 \mathrm{~cm}^{-1}, 470 \mathrm{~cm}^{-1}\right.$, and $430 \mathrm{~cm}^{-1}$, respectively). Assignment of IR spectral bands of clay minerals according to the literature ${ }^{17-19}$ was used in this paper. PC1 described $79.4 \%$ of the variance. PC2 described $10.8 \%$ of the variance, and its loadings spectrum included "negative" bands of kaolinite and the "positive" broad and very weak band at $3400 \mathrm{~cm}^{-1}$ (stretching vibration of water). PC3 described $4.0 \%$ of the variance, and its loadings spectrum contained "negative" bands of kaolinite and the "positive" band of the stretching vibration of water (higher intensity than in PC2).

The band at $1645 \mathrm{~cm}^{-1}$ (in the PC2 and PC3 loadings spectra) belongs to the deformation vibration of water. This band very probably represents moisture in the samples. The band at $1440 \mathrm{~cm}^{-1}$ ("positive" in PC2 and "negative" in PC3 loadings spectra) belonged to carbonates present as impurities in the samples of biotite (Bio3) and dickite (Dic1). The weak intensity of the $1440 \mathrm{~cm}^{-1}$ band in the IR spectra confirms only traces of carbonates in these standards. In PC loadings spectra the intensity of this band rises by reason of significant influence of this band on the variability of spectra. The bands at 1645 $\mathrm{cm}^{-1}$ and $1440 \mathrm{~cm}^{-1}$ were not used for the creation of Model 1 .

The loadings spectra of the first three PCs (PC1, PC2, and PC3) are shown in Fig. 3.

Model 2: Identification of Minerals of the KaolineSerpentine Group. This model was created for identification of individual members of the kaoline-serpentine group of clay minerals. Kaolinite, dickite, and halloysite were used in this study as representatives of the kaoline-serpentine group of clay minerals. Thus, Model 2 included three classes (kaolinite, dickite, and halloysite).

All minerals were clearly classified into the appropriate classes after performance of discriminant analysis. 


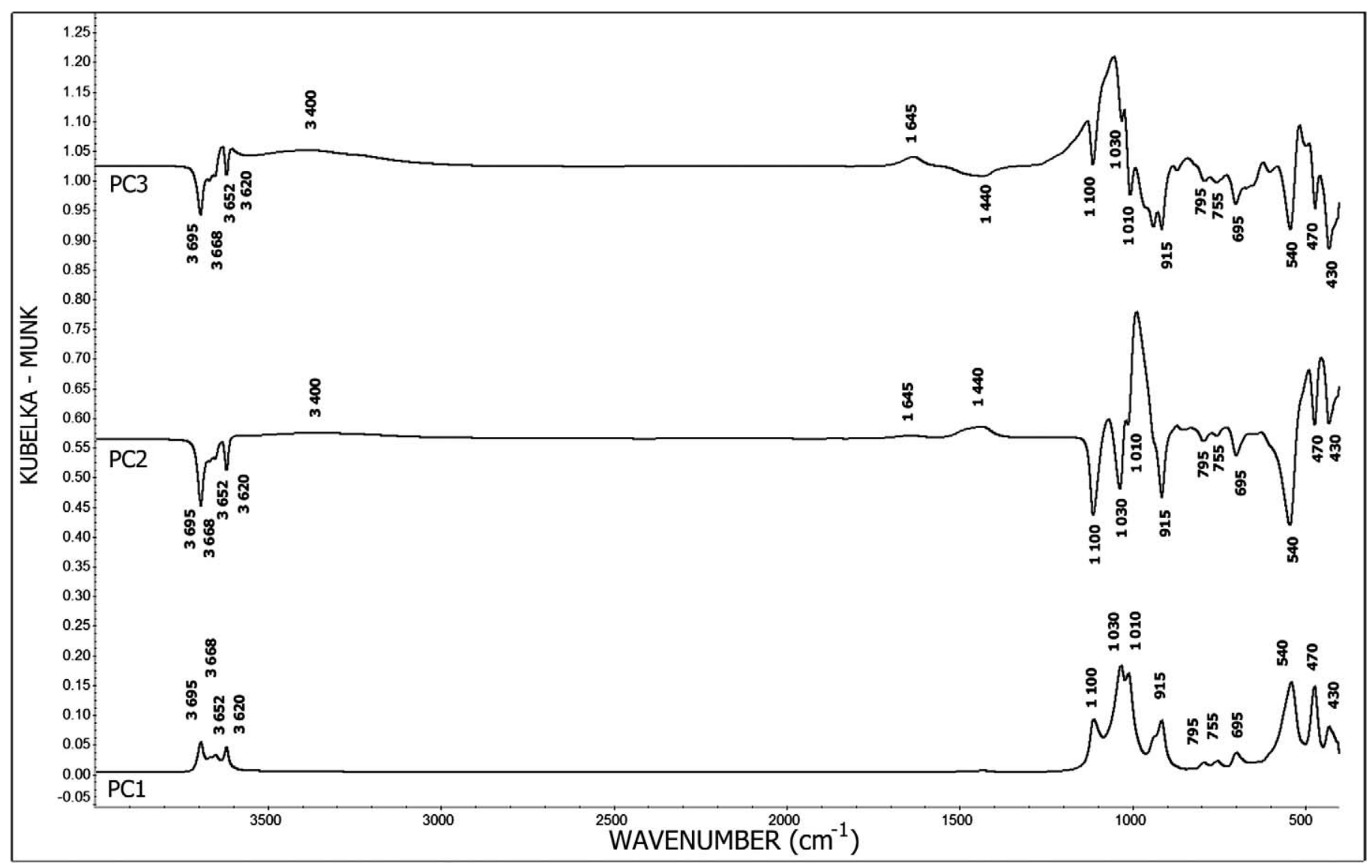

FIG. 3. Loadings spectra of the first three principal components of Model 1.

Ten principal components (PCs) were calculated in Model 2. These ten PCs described $99.9 \%$ of the variance of the spectral information, with nearly $97.5 \%$ of the variance captured in the first three PCs. PC1 described $82.5 \%$ of the variance, PC2 described $11.3 \%$ of the variance, and PC3 described $3.6 \%$ of the variance. All three PC loadings spectra included "negative" bands of kaolinite. The particular loadings spectra differed only in the intensities of their bands. Bands of the highest intensities were in the PC1 loadings spectrum. The PC1 loadings spectrum includes all bands of kaolinite as well as the PC1 loadings spectrum in Model 1 (but "negative"). The bands of kaolinite visible in the PC2 loadings spectrum were the ones at $795 \mathrm{~cm}^{-1}, 755 \mathrm{~cm}^{-1}, 695 \mathrm{~cm}^{-1}, 540 \mathrm{~cm}^{-1}, 470 \mathrm{~cm}^{-1}$, and 430 $\mathrm{cm}^{-1}$. The bands of kaolinite visible in the PC3 loadings spectrum were the ones at $1100 \mathrm{~cm}^{-1}, 1030 \mathrm{~cm}^{-1}, 1010 \mathrm{~cm}^{-1}$, $915 \mathrm{~cm}^{-1}, 695 \mathrm{~cm}^{-1}, 540 \mathrm{~cm}^{-1}, 470 \mathrm{~cm}^{-1}$, and $430 \mathrm{~cm}^{-1}$.

The band at $1440 \mathrm{~cm}^{-1}$ ("negative" intensity in PC2 loadings spectrum and "positive" intensity in PC3 loadings spectrum) belongs to the stretching vibration of carbonates present as impurities in the sample of dickite (see description of Model 1). This band was not used for the creation of Model 2.

The loadings spectra of the above-mentioned PCs (PC1, PC2, and PC3) of Model 2 are shown in Fig. 4.

Model 3: Identification of Minerals of the Smectite Group. Model 3 was created for identification of individual members of the smectite group of clay minerals. $\mathrm{Na}-$ montmorillonite, $\mathrm{Ca}$-montmorillonite, nontronite, and hectorite were used in this study as representatives of this group of clay minerals. Model 3 included five classes (Na-montmorillonite, $\mathrm{Ca}-$ montmorillonite, nontronite, hectorite, and mixed illitesmectite structure).

All minerals were classified into the appropriate classes after performance of discriminant analysis.

Ten principal components (PCs) were calculated in Model 3. These ten PCs described $99.9 \%$ of the variance of the spectral information, with nearly $97.5 \%$ of the variance captured in the first three PCs. The loadings spectrum of the first principal component (PC1) included spectral bands of montmorillonite only: the stretching band of structural hydroxyl groups (3640 $\left.\mathrm{cm}^{-1}\right)$, the broad stretching band of water $\left(3440 \mathrm{~cm}^{-1}\right)$, the deformation band of water $\left(1650 \mathrm{~cm}^{-1}\right)$, the band of $\mathrm{Si}-\mathrm{O}$ stretching $\left(1040 \mathrm{~cm}^{-1}\right)$, the deformation band of the Al-Al$\mathrm{OH}$ vibration $\left(915 \mathrm{~cm}^{-1}\right)$, the deformation band of the $\mathrm{Al}-\mathrm{Mg}-$ $\mathrm{OH}$ vibration $\left(840 \mathrm{~cm}^{-1}\right)$, the $\mathrm{Si}-\mathrm{O}$ stretching band of silica $\left(800 \mathrm{~cm}^{-1}\right)$, the coupled out-of-plane vibration band of $\mathrm{Al}-\mathrm{O}$ and $\mathrm{Si}-\mathrm{O}\left(625 \mathrm{~cm}^{-1}\right)$, and the deformation bands of $\mathrm{Al}-\mathrm{O}-\mathrm{Si}$ and $\mathrm{Si}-\mathrm{O}-\mathrm{Si}\left(525 \mathrm{~cm}^{-1}\right.$ and $470 \mathrm{~cm}^{-1}$, respectively). PC1 described $86.0 \%$ of the variance. PC2 described $7.2 \%$ of the variance and its loadings spectrum included "negative" bands at $3640 \mathrm{~cm}^{-1}, 3440 \mathrm{~cm}^{-1}$, and $1650 \mathrm{~cm}^{-1}$ and "positive" bands at $800 \mathrm{~cm}^{-1}, 625 \mathrm{~cm}^{-1}, 525 \mathrm{~cm}^{-1}$, and $470 \mathrm{~cm}^{-1}$. PC3 described $4.3 \%$ of the variance and the loadings spectrum contained "negative" bands at $3640 \mathrm{~cm}^{-1}, 3440 \mathrm{~cm}^{-1}, 1650$ $\mathrm{cm}^{-1}, 1040 \mathrm{~cm}^{-1}, 915 \mathrm{~cm}^{-1}, 800 \mathrm{~cm}^{-1}, 625 \mathrm{~cm}^{-1}, 525 \mathrm{~cm}^{-1}$, and $470 \mathrm{~cm}^{-1}$. All bands in the loadings spectra of PC2 and PC3 belonged to montmorillonite as well. 


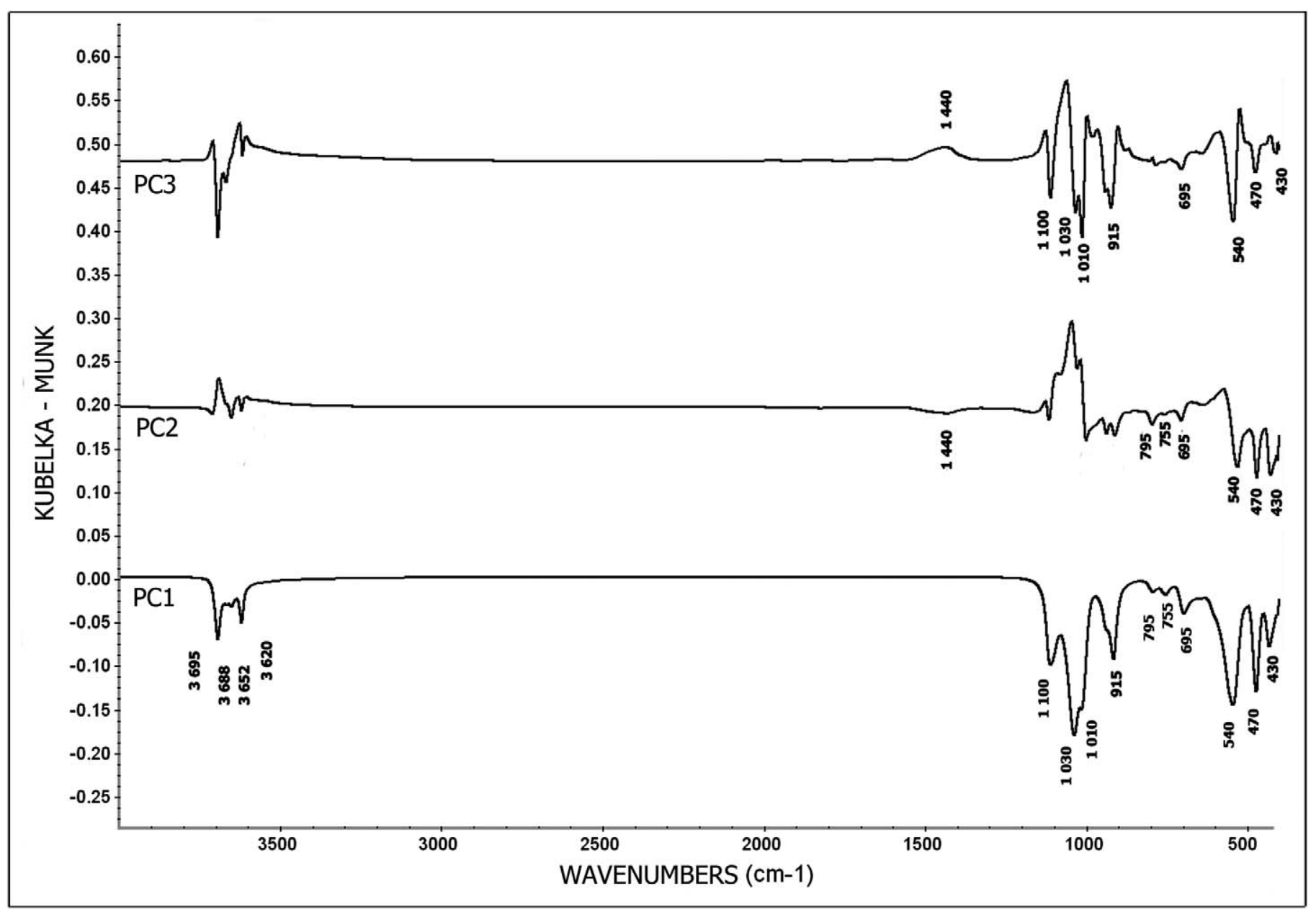

FIG. 4. Loadings spectra of the first three principal components of Model 2.

The band at $1650 \mathrm{~cm}^{-1}$ was not used for creation of Model 3 because of potential interference intensity of this band by moisture in the samples.

The loadings spectra of the above-mentioned PCs (PC1, PC2, and PC3) are shown in Fig. 5.

Model 4: Identification of Minerals in the Mica Group. This model was created for identification of individual members of the mica group. Biotite, muscovite, and illite were used in this study as representatives of this group of clay minerals. Model 4 included four classes (biotite, muscovite, illite, and mixed illite-smectite structure).

All minerals were classified into the appropriate classes after performance of discriminant analysis. The Mahalanobis distance plot for the muscovite and illite classes is shown in Fig. 6.

The clusters of muscovite and illite are relatively close to each other but they are clearly separated in this plot. The IR spectra of muscovite and illite can be very similar (on account of their similar chemical composition and structure) and common identification of these minerals by their IR spectra is practically impossible. ${ }^{5}$

Ten principal components (PCs) were calculated in Model 4. These ten PCs described $99.9 \%$ of the variance of the spectral information, with nearly $97.5 \%$ of the variance captured in the first two PCs. The loadings spectrum of PC1 included the following spectral bands applied to the creation of Model 4: the stretching band of structural hydroxyl groups $\left(3600 \mathrm{~cm}^{-1}\right)$, the band of Si-O stretching $\left(1010 \mathrm{~cm}^{-1}\right)$, the deformation band of the $\mathrm{Al}-\mathrm{Al}-\mathrm{OH}$ vibration $\left(935 \mathrm{~cm}^{-1}\right)$, the deformation band of the $\mathrm{Al}-\mathrm{O}-\mathrm{Si}$ in-plane vibration $\left(755 \mathrm{~cm}^{-1}\right)$, the $\mathrm{Si}-\mathrm{O}$ deformation band $\left(700 \mathrm{~cm}^{-1}\right)$, and the deformation bands of Al-O-Si and Si-O-Si $\left(535 \mathrm{~cm}^{-1}\right.$ and $480 \mathrm{~cm}^{-1}$, respectively). The bands at $3600 \mathrm{~cm}^{-1}, 1010 \mathrm{~cm}^{-1}, 700 \mathrm{~cm}^{-1}$, and $480 \mathrm{~cm}^{-1}$ belonged to biotite; the bands at $3600 \mathrm{~cm}^{-1}, 1010 \mathrm{~cm}^{-1}, 935$ $\mathrm{cm}^{-1}, 755 \mathrm{~cm}^{-1}, 700 \mathrm{~cm}^{-1}, 535 \mathrm{~cm}^{-1}$, and $480 \mathrm{~cm}^{-1}$ belonged to muscovite and illite. PC1 described $90.6 \%$ of the variance. PC2 described $6.8 \%$ of the variance and its loadings spectrum included "negative" bands at $3600 \mathrm{~cm}^{-1}, 935 \mathrm{~cm}^{-1}, 755 \mathrm{~cm}^{-1}$, $535 \mathrm{~cm}^{-1}$, and $480 \mathrm{~cm}^{-1}$.

The band at $1440 \mathrm{~cm}^{-1}$ in both PC loadings spectra belonged to carbonates present as impurities in the sample of biotite (see description of Model 1). The band at $1440 \mathrm{~cm}^{-1}$ was not used for the creation of Model 4.

The loadings spectra of the above-mentioned PCs (PC1 and PC2) are shown in Fig. 7.

\section{CONCLUSION}

The discriminant analysis of IR spectra of 51 samples of clay mineral standards is presented in this paper. Identification of individual clay minerals is possible using the four created 


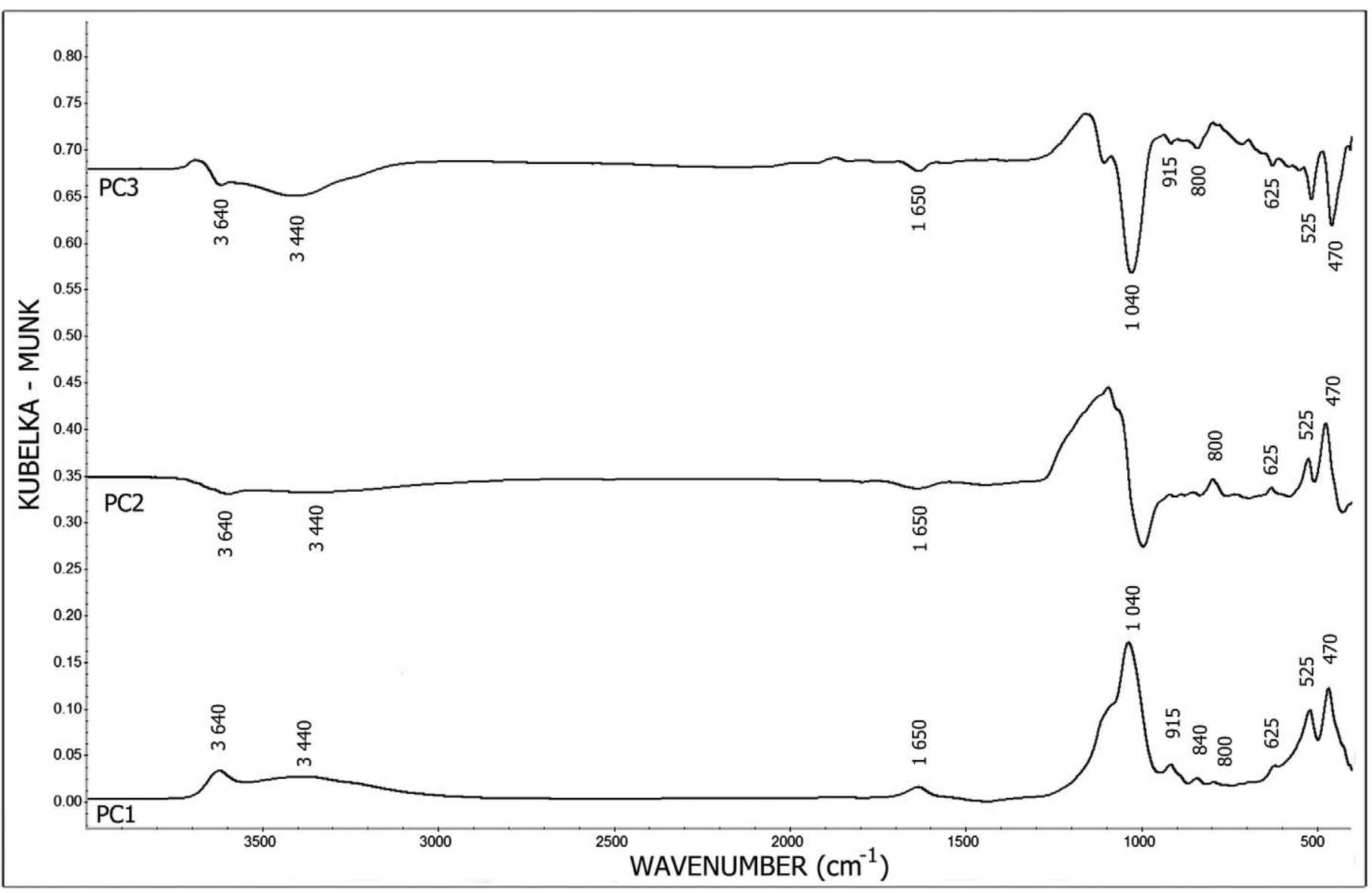

FIG. 5. Loadings spectra of the first three principal components of Model 3.

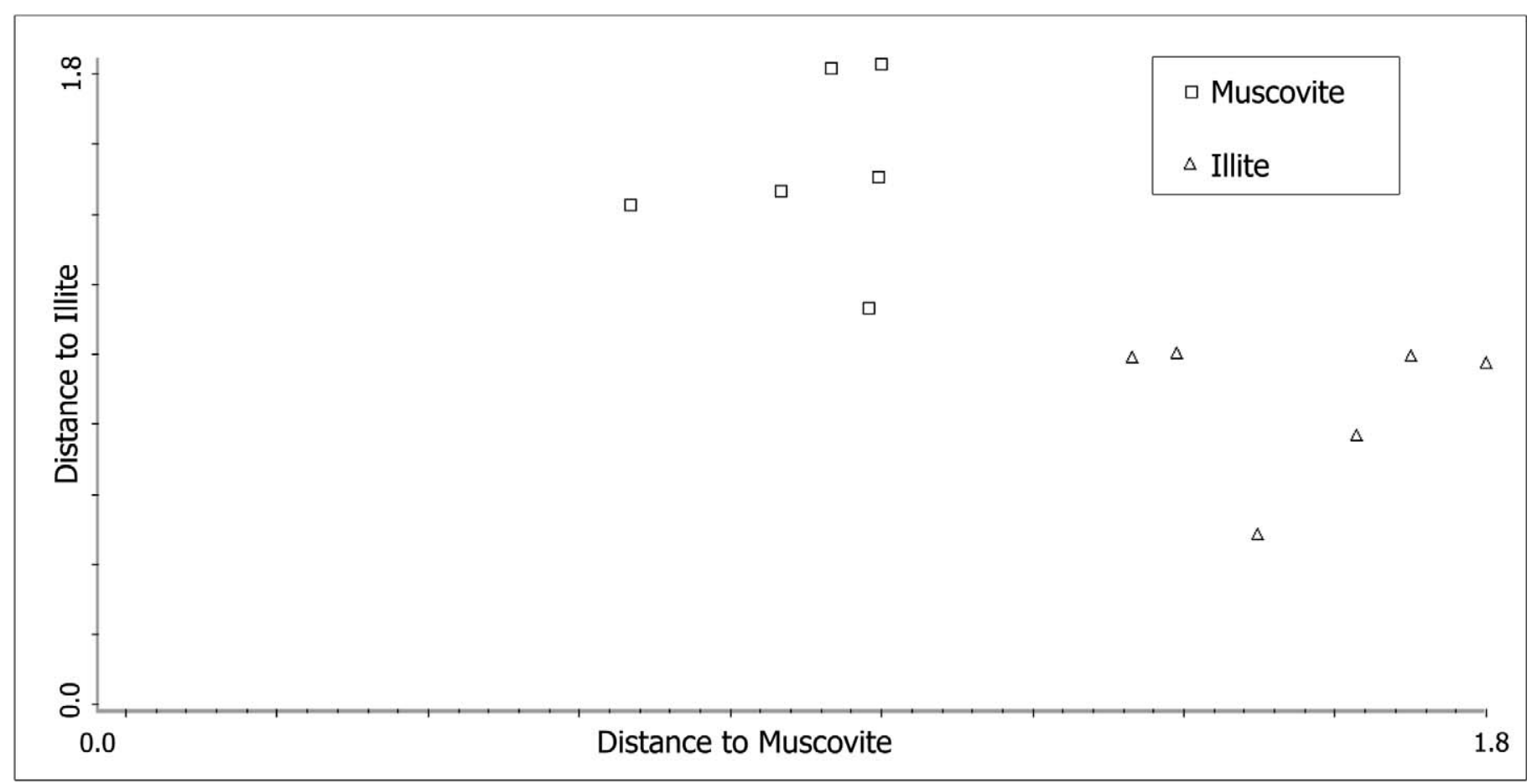

FIG. 6. Mahalanobis distance plot of muscovite and illite classes (Model 4). 


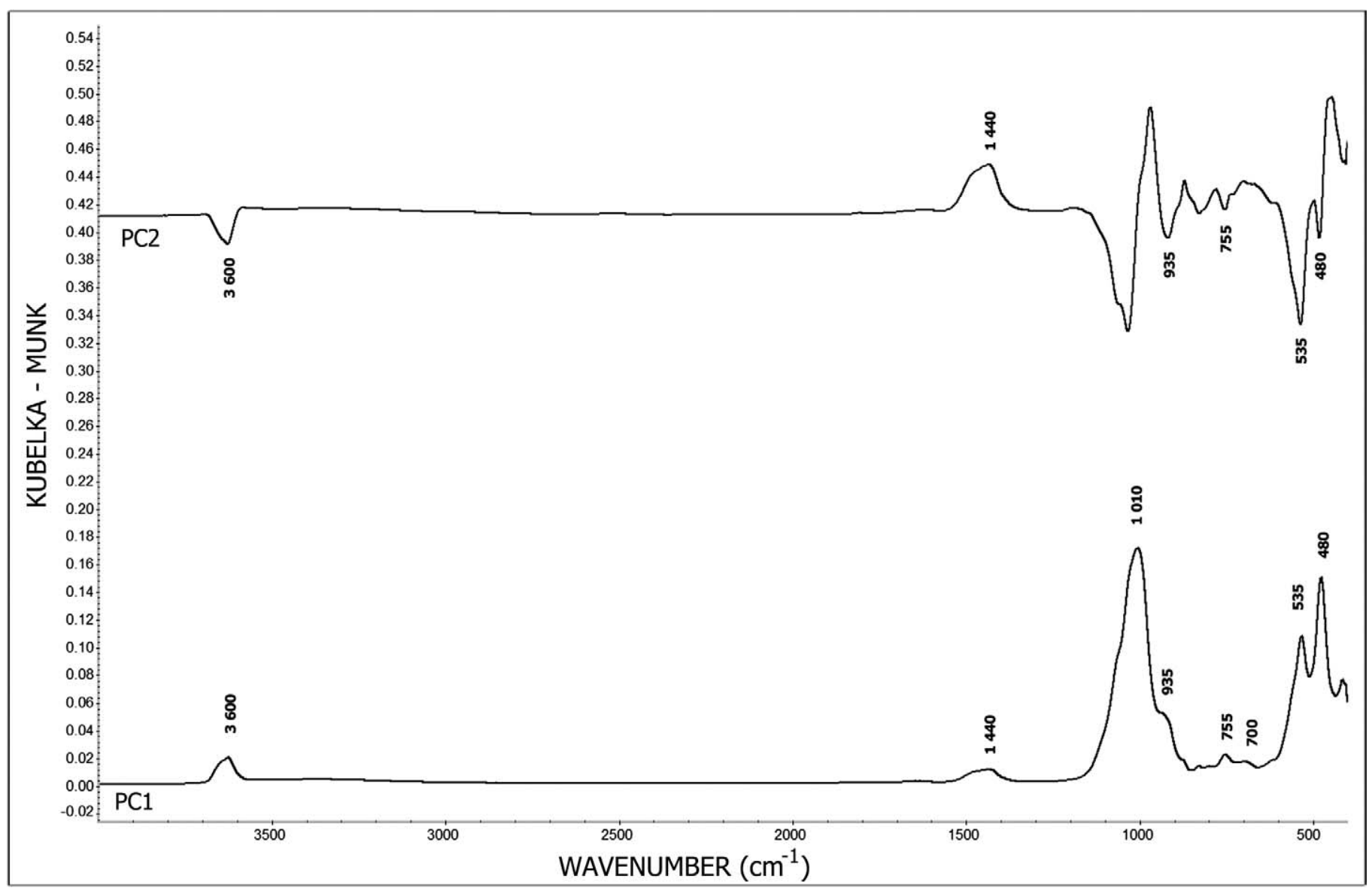

FIG. 7. Loadings spectra of the first two principal components of Model 4.

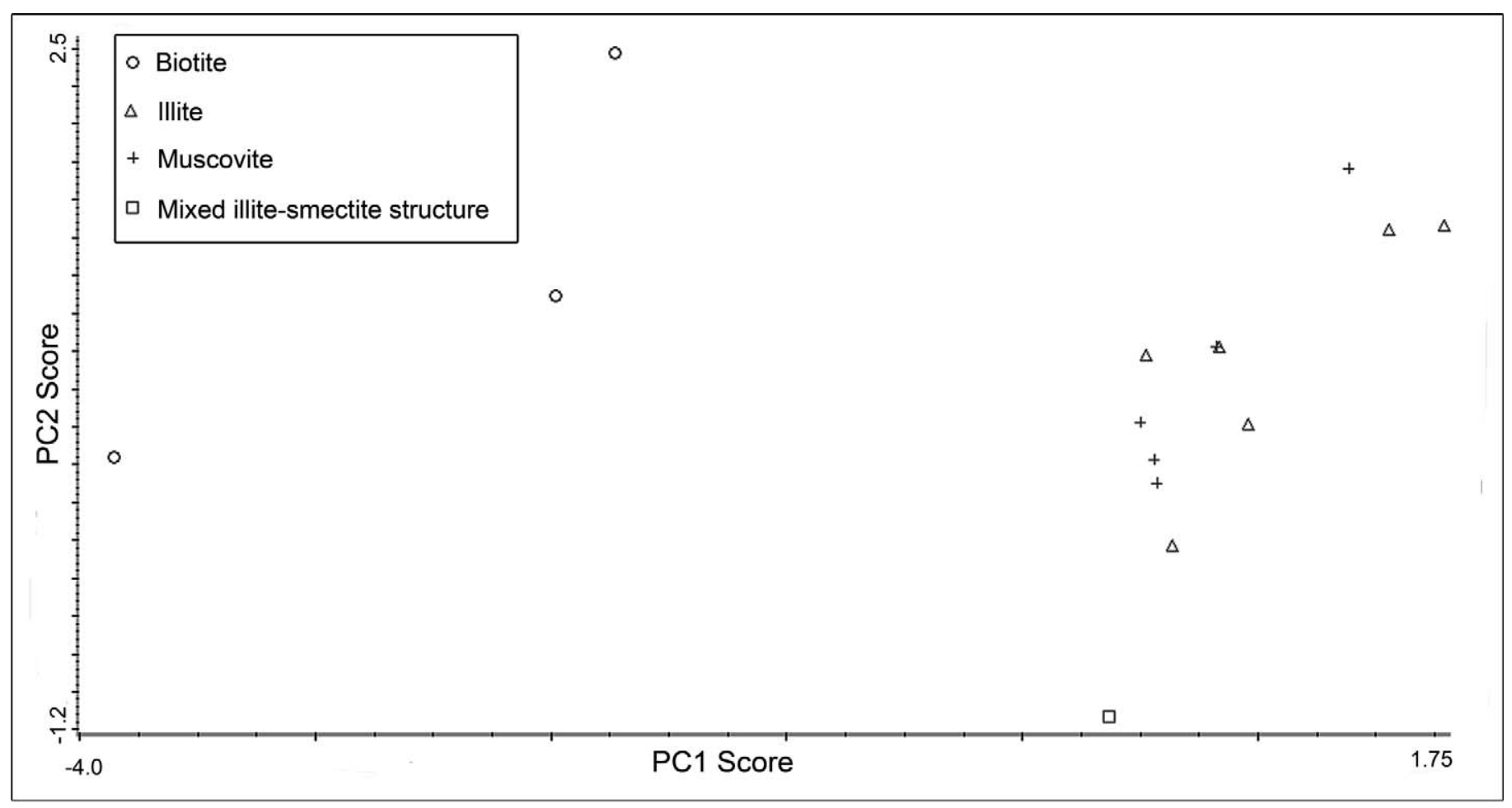

FIG. 8. Score plot of the first two principal components of Model 4. 
statistical models. Model 1 was created for the splitting of clay minerals into individual groups of clay minerals. Model 2, Model 3, and Model 4 were used for the identification of clay minerals from the groups of kaoline-serpentine, smectite, and mica minerals, respectively.

Principle component analysis was not alone sufficient to make clear separation of samples to appropriate classes. The score plot of the first two principle components (PC1 and PC2) of Model 4 is shown as an example (see Fig. 8). Samples of biotite and mixed illite-smectite structure are clearly separated in this score plot. Samples of muscovite and illite do not create separated clusters and samples of these minerals have been mutually mixed in the score plot. Contrary to PCA, discriminant analysis was effective in the classification of all the minerals to the appropriate classes. The task of PCA was rather reduction of redundant spectral information and finding of significant spectral bands for subsequent discriminant analysis. The most important spectral bands of clay minerals found by PCA were vibration bands of hydroxyl groups and vibration bands of $\mathrm{Si}-\mathrm{O}$ and $\mathrm{Al}-\mathrm{O}$ bonds. Also considerably significant were bands of kaolinite in Model 1 and Model 2.

Identification of clay minerals by discriminant analysis of IR spectra was successful in this study. Differentiation of muscovite from illite was even achieved using this method. Muscovite and illite had too similar IR spectra and these two clay minerals are almost indistinguishable when common methods of identification by IR spectroscopy are used. The probable reason for a successful differentiation of muscovite from illite was the use of PCA as a part of the discriminant analysis. Principle component analysis is able to find the very slight differences in the IR spectra of the muscovite and illite standards. Another advantage of discriminant analysis as an identification tool is the ability to identify mixed structures of clay minerals (e.g., the illite-smectite mixed structure).

\section{ACKNOWLEDGMENTS}

This work was supported by the Czech Science Foundation Project No. 105/ 08/1398, Project No. 105/07/P416, and by Research plan No. AVOZ 30860518 .

1. J. Srodon, Mineral. Mag. 66, 677 (2002).

2. H. Kodama, L. S. Kotlyar, and J. A. Ripmeester, Clays Clay Minerals 37, 364 (1989).

3. C. Vogt, J. Lauterjung, and R. X. Fischer, Clays Clay Minerals 50, 388 (2002).

4. S. J. Chipera and D. L. Bish, Clays Clay Minerals 49, 398 (2001).

5. L. Vaculíková, New possibilities of identification of clay minerals and micas in sedimentary rocks using infrared spectroscopy with Fourier transformation (in Czech) (Final Report of Post-Doc Project of Czech Science Foundation, Ostrava, 2006).

6. T. Isaksson and A. H. Aastveit, "Classification Methods", in Handbook of Vibrational Spectroscopy, J. M. Chalmers and P. R. Griffiths, Eds. (John Willey and Sons, Chichester, 2002), vol. 3, pp. 2113-2121.

7. R. D. Maesschalck, D. Jouan-Rimbaud, and D. L. Massart, Chemom. Intell. Lab. Syst. 50, 1 (2000).

8. T. Fearn, "Discriminant Analysis", in Handbook of Vibrational Spectroscopy, J. M. Chalmers and P. R. Griffiths, Eds. (John Willey and Sons, Chichester, 2002), vol. 3, pp. 2087-2090.

9. M. Meloun and J. Militký, Statistical Analysis of Experimental Data (in Czech) (Academia, Praha, 2004), 2nd ed., pp. 301-405.

10. J. Hendl, Review of statistical methods of data processing (in Czech) (Portál, Praha, 2006), 2nd ed., pp. 486-484.

11. S. Tesch and M. Otto, Fuel 74, 978 (1995).

12. D. B. Dahlberg, S. M. Lee, S. J. Wenger, and J. A. Vargo, Appl. Spectrosc. 51, 1118 (1997).

13. A. Kher, M. Mulholland, B. Reedy, and P. Maynard, Appl. Spectrosc. 55, $1192(2001)$.

14. S. Tsuchikawa, K. Inoue, J. Noma, and K. Hayashi, J. Wood Sci. 49, 29 (2003).

15. M. Ritz, Vib. Spectrosc. 43, 319 (2007).

16. Z. Wiess and M. Kužvart, Clay Minerals-their nanostructure and utilization (in Czech), (Karolinum, Praha, 2005), p. 29.

17. J. Madejová and P. Komandel, Clays Clay Minerals 49, 410 (2001).

18. J. D. Russel and A. R. Fraser, "Infrared Methods", in Clay Mineralogy: Spectroscopic and Chemical Determinative Methods, M. J. Wilson, Ed. (Chapman and Hall, London, 1994), Chap. 2, pp. 19-39.

19. L. Vaculíková and E. Plevová, Acta Geodyn. Geomater. 2, 163 (2005). 